\title{
DEFENSE EXERCISE MODEL OF VOLLEYBALL FW FOR BEGINNER
}

\author{
Fatirul Wa'asil ${ }^{1}$, Hernawan ${ }^{2}$, Hidayat Humaid ${ }^{3}$ \\ 1,2,3Pendidikan Jasmani Pascasarjana, Universitas Negeri Jakarta \\ 1e-mail: fatiroel02@gmail.com
}

\begin{abstract}
Abstrak
Tujuan yang ingin dicapai dari penelitian dan pengembangan ini adalah untuk menghasilkan produk model latihan bertahan bolavoli untuk pemula. Penelitian dan pengembangan ini dilakukan untuk dapat memperoleh informasi tentang pengembangan dan penerapan model latihan bertahan bolavoli untuk pemula serta untuk mengetahui efektivitas model yang dihasilkan. Penelitian ini menggunakan metode Research \& Development (R\&D) dari Borg and Gall. Subyek dalam penelitian ini adalah siswa ekstrakurikuler SMP yang terdiri dari 30 siswa / atlet. Tahapan-tahapan dalam penelitian ini adalah: analisis kebutuhan, evaluasi ahli (evaluasi produk awal), ujicoba kelompok kecil, dan ujicoba kelompok besar (field testing). Uji efektivitas model menggunakan tes bertahan bolavoli yang digunakan untuk mengetahui tingkat kemampuan bertahan siswa ekstrakurikuler sebelum dan sesudah pemberian perlakuan model latihan bertahan yang dikembangkan. Tes awal yang dilakukan diperoleh tingkat kemampuan bertahan siswa / atlet adalah 45.40. Setelah diberikan perlakuan model latihan bertahan didapatkan tingkat kemampuan bertahan 51.77. Pada uji signifikan perbedaan dengan spss 16 didapatkan mean $=-6.37$ menunjukan selisih dari hasil pre-test dan hasil post-test, hasil t-hitung $=-6.291 \mathrm{df}=29$ dan $\mathrm{p}$-value $=0.00<0.05$ yang berarti terdapat perbedaan yang signifikan antara sebelum dan sesudah diberikan perlakuan model latihan bertahan bolavoli. Dengan demikian model latihan bertahan bolavoli untuk pemula efektif untuk meningkatkan kemampuan bertahan bolavoli.
\end{abstract}

Kata Kunci : Model, Latihan, Bolavoli, Bertahan

\begin{abstract}
The aim of this research and development is to products model volleyball defense for amateur. Research and development is carried out in order to obtain information about the development and application of models for beginner volleyball defense as well as to determine the effectiveness of the resulting model. This study uses Research \& Development $(R \& D)$ from Borg and Gall. The subjects in this study were junior high school extracurricular students consisting of 30 students / athletes. The stages of this research are: analysis of needs, the expert evaluation (initial product evaluation), testing of small groups, and testing large groups (field testing). Model effectiveness test using volleyball defense test is used to determine the level of survival ability of extracurricular students before and after the treatment of defense training models developed. The initial test conducted was obtained by the student's / athlete's ability to survive was 45.40 . After being given the treatment model for defense training, it was found that the ability to defense was 51.77. In the significant test of differences with spss 16, it was found that the mean $=-6.37$ showed the difference from the results of the pretest and post-test results, the results of t-count $=-6.291 \mathrm{df}=29$ and $p$-value $=$ $0.00<0.05$ which means there is a significant difference between before and after being given the treatment model of the defense exercise volleyball. Thus the
\end{abstract}


training model for volleyball for beginners is effective to improve the ability to defense volleyball.

Keywords: Models, Exercise, Volleyball, Defense

\section{PENDAHULUAN}

Olahraga bolavoli merupakan cabang olahraga yang telah meraih prestasi ditingkat nasional dan internasional. Permainan ini merupakan cabang olahraga beregu yang dimainkan oleh enam orang setiap regu dan permainan ini akan berjalan dengan baik apabila setiap pemain minimal telah menguasai teknik dasar bermain bolavoli. Disetiap negara berkembang akan menaruh perhatian besar terhadap perkembangan olahraga di negaranya, karena olahraga tidak hanya berperan meningkatkan kesegaran jasmani dan prestasi olahraga suatu bangsa akan tetapi mengharumkan nama bangsa sendiri. Kepopuleran olahraga ini tampak dari sarana dan prasarananya yang ada di pedesaan maupun di kota serta berbagai kegiatan-kegiatan yang diselenggarakan dalam kejuaraan seperti, kejuaraan antar sekolah, kejuaraan pekan olahraga pelajar daerah (POPDA), kejuaraan pekan olahraga pelajar nasional (POPNAS), dan kejuaraan olimpiade olahraga siswa nasional (O2SN). Pemain bolavoli tentunya menginginkan prestasi yang tinggi dalam kejuaraan bolavoli tersebut.

Bolavoli merupakan salah satu permainan bola besar beregu yang menyenangkan. Dimana melibatkan lebih dari satu orang pemain, setiap pemain dari setiap regu mempunyai tujuan tertentu baik untuk kesenangan maupun untuk kemenangan. Dalam permainan bolavoli ada beberapa bentuk teknik dasar yang harus dikuasai. Teknik-teknik dalam bolavoli terdiri atas servis, passing bawah, passing atas, block, dan smash. Melatih teknik dasar bermain bola voli sebaiknya sudah dilakukan sejak remaja dimana hal ini akan memberikan perasaan yang baik pada setiap pemain untuk mengkoordinasikan setiap teknik menjadi sebuah gerakan yang indah.

Permainan bolavoli merupakan permainan yang membutuhkan kerjasama tim. Kerjasama tim dapat dilihat dari lini depan maupun belakang, yaitu pola pertahanan yang dibuat secara baik antara pemain penyerang yang melakukan 
block dengan pemain bertahan belakang menerima bola dari lawan untuk memberikan pengembalian bola kepada pengumpan dengan baik untuk diolah menjadi sebuah serangan balik dan menghasilkan poin. Pemain bertahan membutuhkan kemampuan bertahan yang baik untuk membuat serangan yang baik untuk mendapatkan poin. Teknik-teknik bertahan yaitu teknik bertahan dari serangan smash dan teknik bertahan dari serangan tipuan.

Bertahan memegang peranan yang sangat penting dalam permainan bolavoli. Keterampilan bertahan harus dipelajari dan dikuasai oleh setiap pemain. Keterampilan tersebut didapat melalui sebuah proses latihan yang panjang dan terus-menerus. Semua pemain harus mempunyai teknik bertahan yang baik untuk meningkatkan efektifitas bertahan dalam bermain bolavoli. Teknik bertahan tidak hanya berguna untuk libero tetapi juga pemain penyerang dan pengumpan pada saat berada diposisi belakang dengan tujuan untuk membuat pertahanan yang baik. Dampaknya dari bertahan yang baik dapat memudahkan pengumpan untuk mengolah sebuah serangan balik. Semakin baik teknik bertahannya semakin memudahkan untuk membuat serangan balik.

Berdasarkan permasalahan di atas peneliti merasa perlu dibuatnya model latihan bertahan yang variatif dan tersusun secara sistematis dari yang termudah sampai pada yang tersulit. Harapannya dari model-model tersebut dapat diterapkan pada saat latihan agar latihan berjalan sesuai dengan yang diharapkan. Model-model latihan tersebut hendaknya dapat disesuaikan untuk pemula. Sehingga bisa menjadi referensi pelatih untuk pemula pada saat proses latihan berjalan.

Berdasarkan uraian latar belakang masalah, maka perumusan masalah dalam penelitian ini yaitu (1) Bagaimanakah model latihan bertahan bolavoli untuk pemula?; (2) Apakah model latihan bertahan bolavoli efektif untuk meningkatkan keterampilan bertahan pada pemula?

Permainan bolavoli merupakan olahraga yang sangat digemari, terbukti hampir diseluruh belahan dunia memainkan olahraga ini. Bolavoli di Indonesia telah merebut hati para pecinta olahraga. Menurut Ahmadi (2007) "bolavoli merupakan suatu permainan yang kompleks yang tidak mudah dilakukan oleh 
setiap orang, sebab dalam permainan bola voli dibutuhkan koordinasi gerak yang benar-benar bisa diandalkan untuk melakukan semua gerakan yang ada dalam permainan bolavoli

Menurut Palao, Santos, dan Urena (2004) menyatakan bahwa "Volleyball is differentiated from the rest of team sports, because although it is a sport with discrete skills (Poulton, 1957), the game has a cyclical and sequential pattern (Beal, 1989).

Bertahan dalam permainan bolavoli tidak hanya menahan serangan lawan melalui smash keras, tetapi juga bertahan dalam mengantisipasi bola tipuan dari pemain lawan. Dalam bertahan ada beberapa teknik yang harus dikuasi bertahan menggunakan dua lengan dengan berdiri, bertahan menggunakan dua lengan dengan bergerak, bertahan menggunakan satu lengan serta bertahan dengan manjatuhkan badan kedepan.

Berdasarkan hasil analisis diatas diharapkan menjadi jawaban mengenai apa kebutuhan yang diperlukan atlet pemula, pertimbangan yang mendasar dalam membuat model latihan adalah tujuan, karakteristik model latihan dengan atlet, serta faktor pertumbuhan dan perkembangan atlet yang akan menjadi titik fokus dari tujuan latihan tersebut.

Iman menjelaskan bahwa Defense adalah suatu sistem pertahanan dalam menghadapi serangan lawan. Shondell dan Reynaud (2002) menyatakan bahwa "Developing individual defensive skills and ball control is a time-consuming part of the practice routine. Repetition of these defensive skills is the only way that players learn to play defense and develop the ball control necessary for a successful counterattack. Successful teams not only defense the attack in the backcourt but also successfully set the dig to an attacker who scores on the counterattack. There are no shortcuts in developing ball control. Teams must spend many hours to develop this aspect of the game".

Proses dari latihan merupakan dasar dari peningkatan efektifitas jasmani. Oleh karena itu, kita harus terlebih dahulu mengerti dan memahami arti dari latihan. Latihan menurut Bompa (2009) adalah "proses dimana seorang atlet dipersiapkan untuk performa tertinggi. 
Lubis (2013) menyatakan bahwa penyusunan atau perencanaan program latihan adalah mengarahkan latihan selama jangka panjang (waktu tertentu). Tujuannya adalah memaksimalkan adaptasi fisiologi, yang pada akhirnya dapat meningkatkan prestasi atau penampilan seorang atlit. Harre dalam Sukadiyanto (2012) menjelaskan bahwa "latihan (training) adalah suatu proses penyempurnaan kemampuan berolahraga dengan pendekatan ilmiah, memakai prinsip prinsip pendidikan yang terencana dan teratur, sehingga dapat meningkatkan kesiapan dan kemampuan olahragawan. Indra adi budiman menyampaikan bahwa Exercise is belived provide the freshnes of the body, which means that provide health care for the culprit.

Berdasarkan pengertian diatas maka dapat disimpulkan bahwa latihan adalah suatu proses yang sistematis, terencana, terukur, dan terprogram dengan prinsip-prinsip latihan yang ilmiah dalam upaya peningkatan kondisii fisik atau pun keterampilan.

Herman (2010) mengungkapkan Latihan atau melatih kondisi fisik atlet adalah suatu upaya yang sistematis dan ditunjukkan kepada peningkatan kemampuan fungsional atlet sesuai dengan tuntunan cabang olahraga yang ditekuni sehingga dapat mencapai standar yang telah ditentukan.

Roger Buckley dan Caple (2009) menyatakan latihan adalah A planned and systematic effort to modify or develop knowledge/skill/ attitude through learning experience, to achieve effective performance in an activity or range of activities. Its purpose, in the work situation, is to enable an individual to acquire abilities in order that he or she can perform adequately a given task or job and realize their potential. Maksud dari latihan menurut Roger Buckley dan Caple (2009) adalah upaya yang terencana dan sistematis untuk memodifikasi atau mengembangkan pengetahuan, keterampilan, dan sikap melalui pengalaman belajar untuk mencapai kinerja yang efektif dalam suatu kegiatan atau berbagai kegiatan. Tujuannya adalah untuk memungkinkan seseorang memperoleh kemampuan agar dia dapat melakukan pekerjaan dengan benar dan menyadari potensi mereka. 
Penelitian bertujuan untuk mengetahui hasil dari penelitian pengembangan adalah menghasilkan produk baru yang selanjutnya akan dipakai dalam kegiatan melatih untuk mempermudah pelatih dalam menyampaikan materi latihan serta mempermudah pelatih untuk mencapai tujuan yang diharapkan. Penelitian model latihan bertahan pada permainan bolavoli untuk pemula.

\section{METODE}

Penelitian ini menggunakan penelitian jenis Research and Development (penelitian dan pengembangan). Penelitian pengembangan merupakan suatu penelitian yang mendasarkan pada pembuatan suatu produk yang efektif, diawali dengan analisis kebutuhan, pengembangan produk dan uji coba produk. Pada proses pengembangan peneliti tetap melakukan observasi dari perancangan produk tersebut sampai pada saat uji produk di lapangan. Dengan demikian, penelitian pengembangan mencakup evaluasi, sumatif dan konfirmatif.

Prosedur penelitian pengembangan pada dasarnya terdiri dari dua tujuan utama, yaitu mengembangkan produk dan menguji keefektifitasan produk dalam mencapai tujuan. Tujuan pertama disebut sebagai fungsi pengembangan sedangkan yang kedua disebut sebagai validasi. Secara konseptual, pendekatan penelitian, dan pengembangan mencakup sepuluh langkah umum, sebagaimana diuraikan Borg and Gall (1983) yang disajikan pada gambar 1.

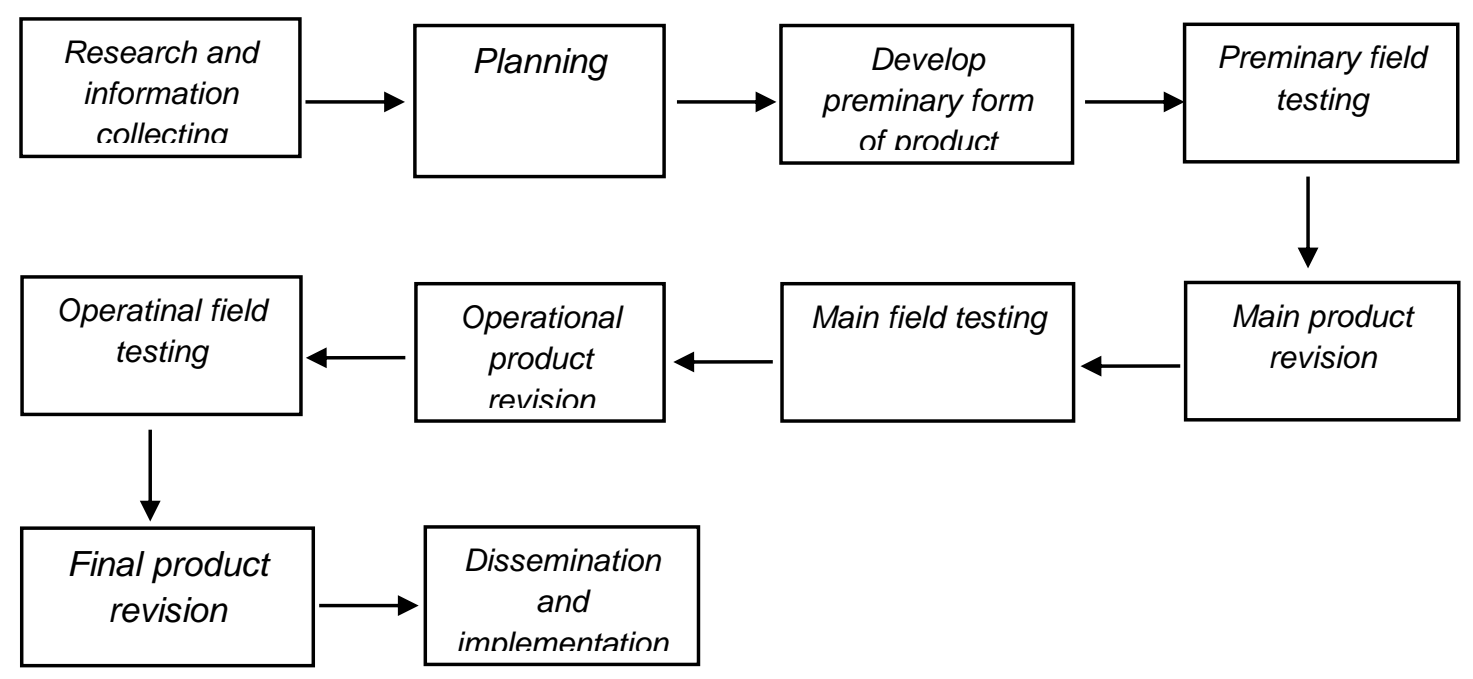

Gambar 1. Desain Pengembangan Bog and Gall (1983) 
Penelitian pengembangan merupakan penelitian yang tidak digunakan untuk menguji teori. Menurut Tangkudung (2016) penelitian dan pengembangan adalah penelitian yang dipergunakan untuk menciptakan produk baru atau mengembangkan produk yang telah ada berdasarkan analisis kebutuhan yang terdapat dilapangan (observasi, wawancara, kuisioner kebutuhan awal).

Penelitian pengembangan model latihan bertahan bolavoli menggunakan model penelitian dan pengembangan (Research and Development) dari Borg dan Gall yang terdiri dari sepuluh langkah dalam penelitian, antara lain: (1) Research and information collecting, (2) Planning, (3) Development of the preliminary from of product, (4) Preliminary field testing, (5) Main product revision, (6) Main field test, (7) Operational product revision, (8) Operational field testing, (9) Final produk, dan (10) Dissemination and implementation. Dalam penelitian ini pada ujicoba kelompok kecil melibatkan subjek sebanyak 20 orang siswa ekstrakurikuler bolavoli pada Sekolah Menengah Pertama Negeri 9 Pontianak. Pada ujicoba kelompok besar melibatkan subjek sebanyak 40 orang siswa ekstrakurikuer bolavoli pada Sekolah Menengah Pertama Negeri 1 Pontianak. Serta pada uji efektifitas produk melibat subjek sebanyak 30 orang siswa ekstrakurikuler bolavoli pada Sekolah Menengah Pertama Negeri 11 Pontianak.

\section{HASIL DAN PEMBAHASAN}

Hasil rata-rata bertahan bolavoli kelompok ekperimen sebelum diberikan perlakuan dengan model latihan (pretest) adalah 45.40 dan setelah diberikan perlakuan dengan model latihan (posttest) adalah 51.77. Berdasarkan Hasil ratarata dari pretest dan posttest dapat ditarik sebuah kesimpulan terdapat peningkatan hasil bertahan atlet setelah diberikan perlakuan dengan model latihan.

Pada uji signifikan perbedaan menggunakan spss 16 didapat mean $=-6.37$ t-hitung $=-6.29$, df $=29$ dan $\mathrm{p}$-value $=0.00<0.05$ yang artinya terdapat perbedaan yang signifikan latihan bertahan siswa / atlet antara sebelum dan sesudah adanya pemberian perlakuan model latihan bertahan bolavoli FW.

Pada uji signifikan perbedaan dengan spss 16 antara kelompok kontrol dan kelompok perlakuan didapatkan mean kelompok kontrol $=-0.567$ mean kelompok 
perlakuan $=-6.37$ menunjukan selisih dari hasil kelompok kontrol dan kelompok eksperimen, hasil t-hitung kelompok kontrol $=-1.292$, df $=29$ dan $\mathrm{p}$-value $=$ $0.207>0.05$ sedangkan hasil t-hitung kelompok perlakuan $=-6.291 \mathrm{df}=29 \mathrm{p}$ value $0.00<0.05$ maka dapat disimpulkan bahwa terdepat perbedaan yang signifikan antara kelompok yang diberi perlakuan dan kelompok kontrol.

\section{SIMPULAN}

Berdasarkan data yang peneliti peroleh dari hasil ujicoba lapangan dan pembahasan hasil penelitian dapat ditarik kesimpulan bahwa:

1. Menghasilkan produk akhir berupa model latihan bertahan untuk pemula terdiri dari 19 item model latihan bertahan.

2. Model latihan bertahan bolavoli untuk pemula dapat mempermudah proses latihan dan meningkatkan hasil bertahan yang bervariasi serta efektif untuk bertahan dari serangan smash dan tipuan.

\section{DAFTAR PUSTAKA}

Ahmadi, N. 2007. Panduan Olahraga Bolavoli. Surakarta: Era Pustaka Utama.

Bompa, T. 2009. Periodization Theory and Methodology of Training. United States: Human Kinetic.

Borg, W., R., and Gall M.D. 1983. Educational Research: An Introduction. New York: Longman Inc.

Buckley, R. Caple, J. 2009. The Theory \& Practice of Training. London: Kogan Page.

Herman. 2010. Jurnal ILARA, Volume I, Nomor 2, Desember.

Palao, J., M., Santos, J. A., \& Ureña, A. 2004. Effect of team level on skill performance in volleyball. International Journal of Performance Analysis of Sport, 4 (2).

Lubis, J. 2013. Panduan Praktis Penyusunan Program Latihan. Depok: Raja Grafindo Persada.

Shondell, D \& Reynaud, C. 2002. The Volleyball Coaching Bible. United States of America: Human Kinetics.

Sukadiyanto. 2012. Pengantar Teori dan Metodologi Melatih Fisik. Bandung: Lubuk Agung.

Tangkudung, J. 2016. Macam-Macam Metodologi Penelitian Uraian dan Contohnya. Jakarta: Lensa Media Pustaka Indonesia. 